\title{
Non-Automatic Weighing Instruments Calibration: Parametric Methods for Outliers Assessments
}

\author{
José Daniel Hernández-Vásquez ${ }^{1, *}$, Cristian Pedraza-Yepes ${ }^{2}$, Ronald Barrios-Castillo ${ }^{2}$, Mauro Castañeda- \\ Escorcia $^{2}$ and Jorge González-Coneo ${ }^{2}$ \\ ${ }^{I}$ Universidad Antonio Nariño. Faculty of Mechanical, Electronic and Biomedical Engineering (FIMEB). Research Group \\ GIFOURIER. Puerto Colombia, Colombia. \\ ${ }^{2}$ Universidad del Atlántico. Faculty of Engineering. Mechanical Engineering Program. Research Group CONFORMAT. Puerto \\ Colombia, Colombia.
}

Received 26 June 2019; Accepted 10 June 2020

\begin{abstract}
In the experimental calibration processes, several error of measure can be obtained. Usually, these values are called as outliers. The outliers impact in the instruments' metrological reliability and, consequently, in the industrial processes' quality control. In specific terms, for mass metrology, the outliers are extremely critic, due to sensibility of technology used for this industry, i.e.: non-automatic weighing instruments (scales). The EURAMET/cg-18/v.02 is the international standard that defined procedure and tests for to assessment the metrological reliability of scales, however, a statistical treatment for outliers is not defined. In order to propose robust alternatives for outliers analyses, this work to evaluate parametric techniques for the elimination of outliers in the calibration of a Bernalo non-automatic weighing instruments (Capacity: $30.000 \mathrm{~kg}$; Resolution: $0.001 \mathrm{~kg}$ ). Three methods were applied in the analysis of experimental data: Dixon, Grubbs and Chauvenet. The results confirmed a reduction in the expanded uncertainty associated to mass measurement $(\mathrm{k}=2)$ up to: $17.6 \%$ (Dixon); $19.9 \%$ (Grubbs) and 35.2\% (Chauvenet). According to the results and considering the contribution of work to applied mass metrology, the authors propose the inclusion of analyzes and evaluation of outliers in the EURAMET/cg-18/v.02. Thus, it is expected an increase in metrological reliability in mass measurement processes at the scientific and industrial sector.
\end{abstract}

Keywords: Applied Metrology, Metrological Reliability, Outliers, Non-Automatic Weighing Instruments, Calibration.

\section{Introduction}

The measurement of mass is an important physical quantity for laboratories and industrial process that must be controlled from non-automatic weighing instruments (scale). The International Organization of Legal Metrology (OIML) R-761 [1] define a procedure of calibration for this technology. This document states that five tests are necessary to calibrate a scale, as: repeatability, eccentric loading, weight, auxiliary verification device and substitution of standard weights at verification. Even though, this procedure is common and applied for different metrology laboratories in many countries, it has some technical and economics disadvantages for industries processes, for example: an industrial process is controlled by a digital scale (Cap.: $300 \mathrm{~kg}$ ). The maximum weight in the process is $200 \mathrm{~kg}$. The scale must be calibrated up to $300 \mathrm{~kg}$ despite the fact that the scale is not used in this range. The economic impact in this case is worse for smaller companies. Thus, since 2009 the European Association of National Metrology Institutes (EURAMET) has published an international recommendation to calibrate scales, as: EURAMET/cg-18/v.02 [2] that allows some flexibilities for industrial processes, e.g.: a scale could be calibrate up to the measurement range that it is used in the industrial process.

\footnotetext{
*E-mail address: johernandez79@uan.edu.co

ISSN: $1791-2377$ @ 2020 School of Science, IHU. All rights reserved.

doi:10.25103/jestr. 135.20
}

Nevertheless, both recommendations (OIML R-76-1 and EURAMET/cg-18/v.02) do not take into consideration an important and undesirable factor that could appear during the calibration process called outliers. These values tend to increase a measurement uncertainty, systematic error and allow that a determined instrument will not be according to the international standard $[3,4]$.

Therefore, the aim of this paper is to analyses metrologically three parametric approaches to evaluate outliers [5] in the scales calibration: Dixon, Chauvenet and Grubbs. Moreover, the results are expected to contribute for the advancement of knowledge of applied mass metrology.

\section{Theoretical Fundamentals}

This paper proposes to study the performance of three different parametric methods for to eliminate outliers. In order to get this objective, the principal assumption is a Gaussian behavior of the experimental data. Thus, it was possible to apply these methods.

\subsection{Dixon test}

Dixon test is a parametric method to eliminate outliers. This method consider a test statistic $\boldsymbol{Q}_{c a l}$ and compare it with a tabulated critical value $\left(\boldsymbol{Q}_{\text {crit }}\right)$. If $\boldsymbol{Q}_{\text {cal }} \geq \boldsymbol{Q}_{\text {crit }}$ the suspect value 
must be eliminated. For $8 \leq \mathrm{n} \leq 12, \boldsymbol{Q}_{\text {cal }}$ can be calculated as in the Eq. 1:

$$
Q=\frac{x_{2}-x_{1}}{x_{n-1}-x_{1}}
$$

\subsection{Chauvenet test}

This method establishes that a $\boldsymbol{x}_{\boldsymbol{i}}$ value measured must be eliminated when $\boldsymbol{r}$ parameter is greater that $\boldsymbol{R}_{\boldsymbol{c}}$ which it is tabulated for Chauvenet test. The $r$ parameter can be calculated applying Eq. 2:

$$
r=\frac{\left|x_{i}-\bar{x}\right|}{s(x)}
$$

\subsection{Grubbs test}

For an experiment which has a data series $\boldsymbol{g}_{i}$ for $\boldsymbol{i}=1,2, \ldots, \mathrm{n}$, configured ascendingly, the equation (3) is applied to detect outliers:

$$
G_{C}=\frac{\left(g_{i}-\bar{g}\right)}{s}
$$

The $\boldsymbol{G}_{\boldsymbol{c}}$ parameter is compared with a critical value $\left(\boldsymbol{G}_{\text {crit }}\right)$ which it is tabulated for Grubbs test, considering a specifically significance level. Outliers are detected when $\boldsymbol{G}_{c}>\boldsymbol{G}_{\text {crit }}$.

\section{Experimental Methodology}

This paper evaluate the outliers in a calibration process for a digital scale that is illustrated in Fig. 1.

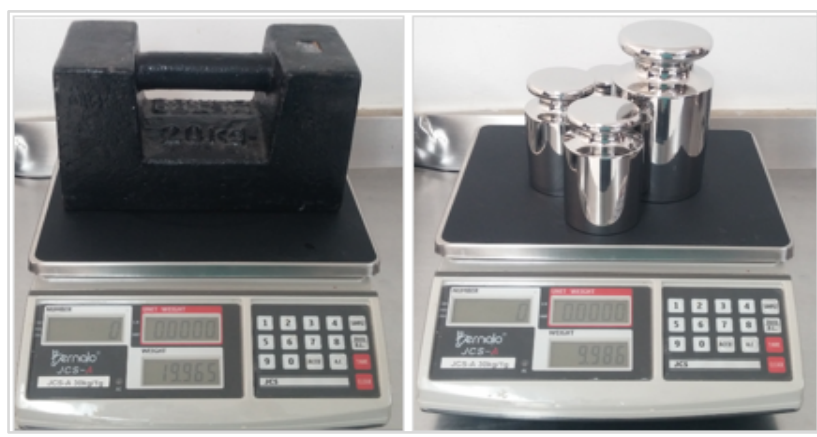

Fig. 1. Bernalo Non-Automatic Weighing Instrument (Capacity: 30.000 $\mathrm{kg}$; Resolution: $0.001 \mathrm{~kg}$ )
At the beginning of the calibration process, it was measured 11 experimental points in the measuring interval (i.e.: total scale capacity). In addition, it was performed 10 repetitions for each experimental point. Besides, atmospheric pressure and environment temperature were measured, respectively, with a barometer $(\mathrm{U}=0.058 \mathrm{mbar} / \mathrm{abs} ; \mathrm{k}=2)$ and thermometer $\left(\mathrm{U}=0.25^{\circ} \mathrm{C} ; \mathrm{k}=2\right)$ calibrated in an accredited metrology laboratory $[6,7]$. Thus, it was calculated the local air density and the buoyancy factor. Then, it was estimated the sample mean and standard deviation. Then, parametric methods to eliminated outliers were applied on the experimental data. After that, the experimental data were fitted for a polynomial curve and the expanded uncertainty was calculated for a confidential level equal to $95.0 \%$. Finally, authors compared the reduction the expanded uncertainty for the three different methods applied (Dixon, Chauvenet and Grubbs) against the original data.

\section{Results and Discussion}

Applying the experimental methodology described in section 3 , it was possible to realize a statistical analyze. The follows sections show the principal results.

\subsection{Outliers and measurement uncertainty analyses}

Tab. 1 shows the experimental data for each experimental calibration point. Even though, the EURAMET/cg-18/v.02 recommend five experimental point, in order to reduce the measurement uncertainty, in this work was taken ten experimental point. Furthermore, table 1 illustrates some values in yellow highlight that represent the different outliers. These values increase the measurement uncertainty and, probably, the instrument will not be according to the measuring process. In fact, Chauvenet is the most powerful test because the statistical analyses detected and eliminated ten outliers (all the value in yellow highlight). The same way, Grubbs test detected and eliminated seven outliers (i.e.: 2.002; 2.998; 5.998; 9.002; 20.004 and $29.998 \mathrm{~kg}$ ). In contrast, Dixon test eliminated only five outliers and, for this reason, its performance was the weakest. The outliers eliminated through Dixon test are: 2.998; 9.002; 20.004; 22.002 and

\begin{tabular}{|c|c|c|c|c|c|c|c|c|c|c|c|}
\hline \multirow{3}{*}{$\begin{array}{c}\text { Experimental } \\
\text { Calibration } \\
\text { Point } \\
\end{array}$} & \multirow{2}{*}{\begin{tabular}{|c|} 
Standard \\
Mass
\end{tabular}} & \multicolumn{10}{|c|}{ Experimental Data (Measurement) } \\
\hline & & $\# 1$ & $\# 2$ & $\# \mathbf{3}$ & $\# 4$ & $\# 5$ & \#6 & \#7 & $\# 8$ & $\# 9$ & $\# 10$ \\
\hline & kg & kg & kg & kg & kg & kg & kg & kg & kg & kg & kg \\
\hline 1 & 0 & 0.001 & 0.001 & 0.001 & 0.001 & 0.001 & 0.001 & 0.002 & 0.001 & 0.002 & 0.003 \\
\hline 2 & 1 & 1.003 & 1.005 & 1.003 & 1.003 & 1.003 & 1.003 & 1.003 & 1.005 & 1.005 & 1.003 \\
\hline 3 & 2 & 2.002 & 2.004 & 2.004 & 2.004 & 2.004 & 2.004 & 2.004 & 2.004 & 2.004 & 2.003 \\
\hline 4 & 3 & 2.998 & 2.996 & 2.996 & 2.996 & 2.996 & 2.996 & 2.996 & 2.996 & 2.996 & 2.996 \\
\hline 5 & 4 & 4.001 & 4.001 & 4.001 & 4.001 & 4.001 & 4.001 & 4.003 & 4.003 & 4.003 & 4.001 \\
\hline 6 & 5 & 5.000 & 5.000 & 5.000 & 5.000 & 5.000 & 4.999 & 4.999 & 4.999 & 4.999 & 4.999 \\
\hline 7 & 6 & 5.998 & 5.997 & 5.995 & 5.995 & 5.995 & 5.995 & 5.995 & 5.995 & 5.995 & 5.995 \\
\hline 8 & 7 & 7.007 & 7.006 & 7.007 & 7.007 & 7.007 & 7.007 & 7.007 & 7.006 & 7.006 & 7.006 \\
\hline 9 & 8 & 7.992 & 7.995 & 7.992 & 7.992 & 7.992 & 7.992 & 7.992 & 7.995 & 7.995 & 7.995 \\
\hline 10 & 9 & 9.001 & 9.001 & 9.001 & 9.001 & 9.001 & 9.001 & 9.001 & 9.001 & 9.001 & 9.002 \\
\hline 11 & 10 & 10.008 & 10.008 & 10.008 & 10.008 & 10.008 & 10.008 & 10.008 & 10.008 & 10.009 & 10.009 \\
\hline 12 & 20 & 20.002 & 20.002 & 20.002 & 20.002 & 20.002 & 20.002 & 20.002 & 20.002 & 20.002 & 20.004 \\
\hline 13 & 22 & 22.001 & 22.001 & 22.001 & 22.001 & 22.001 & 22.001 & 22.001 & 22.001 & 22.001 & 22.002 \\
\hline 14 & 25 & 24.996 & 24.998 & 24.996 & 24.996 & 24.996 & 24.996 & 24.996 & 24.996 & 24.996 & 24.998 \\
\hline 15 & 30 & 29.997 & 29.997 & 29.997 & 29.997 & 29.997 & 29.997 & 29.997 & 29.997 & 29.997 & 29.998 \\
\hline
\end{tabular}
$29.998 \mathrm{~kg}$.

Table 1. Experimental data of the calibration process 
Using the result of the above table, it was possible applied Eq. 4 for to calculate the sample mean $(\bar{x})$ and Eq. 5 for the standard deviation $(\boldsymbol{s})$ :

$$
\bar{x}=\frac{1}{n} \cdot \sum_{i=1}^{n} x_{i}
$$

$$
S=\left[\frac{1}{n-1} \cdot \sum_{i=1}^{n}\left(x_{i}-\bar{x}\right)^{2}\right]^{\frac{1}{2}}
$$

In order to evaluate the repeatability, the uncertainty type A $\left(\boldsymbol{u}_{\boldsymbol{A}}\right)$ was calculated applied Eq. 6:

$$
u_{A}=\frac{s}{\sqrt{n}}
$$

The literature $[6,7]$ shows that when outliers are eliminated of the experimental data, the $\boldsymbol{u}_{\boldsymbol{A}}$ is reduced up to $31.2 \%$. The results in this work confirm that the expanded uncertainty $\left(\boldsymbol{U}_{\boldsymbol{E}}\right)$ can also be reduced applying parametric methods to eliminate outliers.

In relation to environment temperature $\left(\boldsymbol{T}_{\text {air }}\right)$, it was measured with a calibrated thermometer and its uncertainty $\left(\boldsymbol{U}_{\text {Tair }}=0.25^{\circ} \mathrm{C}\right)$ is reported at the certificate of calibration. The atmospheric pressure $\left(\boldsymbol{P}_{\text {atm }}\right)$ was measured with a barometer calibrated and the uncertainty $\left(\boldsymbol{U}_{\text {Patm }}=\mathbf{0 . 0 5 8}\right.$ $\boldsymbol{m b a r} / \boldsymbol{a b s}$ ) is reported at the certificate of calibration. Finally, the local air density $\left(\boldsymbol{\rho}_{\boldsymbol{a r}}\right)$ was calculated applying the ideal gas law as in Eq. 7:

$$
\rho_{\text {air }}=\frac{P_{\text {atm }}}{R_{\text {air }} T_{\text {air }}}
$$

The expansion series of Taylor described in [8] was applied in the Eq. 7 and the mathematical development is described below:

$$
\begin{aligned}
& U_{\rho_{\text {air }}}^{2}=\left(\frac{\partial \rho_{\text {air }}}{\partial P_{\text {atm }}} \cdot U_{P_{\text {atm }}}\right)^{2}+\left(\frac{\partial \rho_{\text {air }}}{\partial R_{\text {air }}} \cdot U_{R_{\text {air }}}\right)^{2}+\left(\frac{\partial \rho_{\text {air }}}{\partial T_{\text {air }}} .\right. \\
& \left.U_{T_{\text {air }}}\right)^{2}
\end{aligned}
$$

In the expression above, the sensibility coefficients are calculated applying equations 9,10 and 11 :

$$
\begin{aligned}
& \frac{\partial \rho_{\text {air }}}{\partial P_{\text {atm }}}=\frac{1}{R_{\text {air }} \cdot T_{\text {air }}} \\
& \frac{\partial \rho_{\text {air }}}{\partial R_{\text {air }}}=0 \quad \therefore \\
& R_{\text {air }}: \text { Constant of the air (ideal gas) } \\
& \frac{\partial \rho_{\text {air }}}{\partial T_{\text {air }}}=-\frac{P_{\text {atm }}}{R_{\text {air }} \cdot T_{\text {air }}^{2}}
\end{aligned}
$$

Replacing equations 9, 10 and 11 in Eq. 8 it was possible obtained Eq. 12:

$$
\begin{aligned}
& U_{\rho_{\text {air }}}^{2}=\left(\frac{1}{R_{\text {air }} \cdot T_{\text {air }}} \cdot U_{P_{\text {atm }}}\right)^{2}+\left(-\frac{P_{\text {atm }}}{R_{\text {air }} \cdot T_{\text {air }}^{2}} .\right. \\
& \left.U_{T_{\text {air }}}\right)^{2}
\end{aligned}
$$

\begin{tabular}{|c|c|c|c|c|c|c|c|}
\hline $\begin{array}{c}\text { Sample } \\
\text { Mean }\end{array}$ & $\begin{array}{l}\text { Standard } \\
\text { Deviation }\end{array}$ & $\begin{array}{l}\text { Environment } \\
\text { Temperature }\end{array}$ & Uncertainty & $\begin{array}{c}\text { Atmospheric } \\
\text { Pressure }\end{array}$ & Uncertainty & $\begin{array}{l}\text { Density of } \\
\text { air }\end{array}$ & Uncertainty \\
\hline$\overline{\mathrm{x}}$ & $\mathbf{s}$ & $\mathbf{T}_{\text {air }}$ & $\mathbf{U}_{\text {Tair }}$ & $\mathbf{P}_{\text {atm }}$ & $\mathbf{U}_{\text {patm }}$ & $\rho_{\mathrm{ar}}$ & $\mathbf{U}_{\text {par }}$ \\
\hline kg & kg & ${ }^{\circ} \mathrm{C}$ & ${ }^{\circ} \mathrm{C}$ & mbar/abs & mbar/abs & $\mathrm{kg} / \mathrm{m}^{3}$ & $\mathrm{~kg} / \mathrm{m}^{3}$ \\
\hline 0.001 & 0.00070 & 27.9 & 0.25 & 1019.8 & 0.058 & 1.180 & 0.0010 \\
\hline 1.004 & 0.00097 & 27.9 & 0.25 & 1019.8 & 0.058 & 1.180 & 0.0010 \\
\hline 2.004 & 0.00067 & 27.9 & 0.25 & 1019.8 & 0.058 & 1.180 & 0.0010 \\
\hline 2.996 & 0.00063 & 27.9 & 0.25 & 1019.8 & 0.058 & 1.180 & 0.0010 \\
\hline 4.002 & 0.00097 & 27.9 & 0.25 & 1019.8 & 0.058 & 1.180 & 0.0010 \\
\hline 5.000 & 0.00053 & 27.9 & 0.25 & 1019.8 & 0.058 & 1.180 & 0.0010 \\
\hline 5.996 & 0.00108 & 27.9 & 0.25 & 1019.8 & 0.058 & 1.180 & 0.0010 \\
\hline 7.007 & 0.00052 & 27.9 & 0.25 & 1019.8 & 0.058 & 1.180 & 0.0010 \\
\hline 7.993 & 0.00155 & 27.9 & 0.25 & 1019.8 & 0.058 & 1.180 & 0.0010 \\
\hline 9.001 & 0.00032 & 27.9 & 0.25 & 1019.8 & 0.058 & 1.180 & 0.0010 \\
\hline 10.008 & 0.00042 & 27.9 & 0.25 & 1019.8 & 0.058 & 1.180 & 0.0010 \\
\hline 20.002 & 0.00063 & 27.5 & 0.25 & 1019.8 & 0.058 & 1.182 & 0.0010 \\
\hline 22.001 & 0.00032 & 27.5 & 0.25 & 1019.8 & 0.058 & 1.182 & 0.0010 \\
\hline 24.996 & 0.00084 & 27.5 & 0.25 & 1019.8 & 0.058 & 1.182 & 0.0010 \\
\hline 29.997 & 0.00032 & 27.5 & 0.25 & 1019.8 & 0.058 & 1.182 & 0.0010 \\
\hline
\end{tabular}

Replacing Eq. 7 in Eq. 12 obtained the expression for the expanded uncertainty associated to density of the air:

$$
\left(\frac{U_{\rho_{\text {air }}}}{\rho_{\text {air }}}\right)^{2}=\left(\frac{U_{P_{\text {atm }}}}{P_{\text {atm }}}\right)^{2}+\left(\frac{U_{T_{\text {air }}}}{T_{\text {air }}}\right)^{2}
$$

Thus, Tab. 2 summarizes the results obtained in term of the sample mean, standard deviation, environment temperature, atmospheric pressure, air density and their associated uncertainties.

Table 2. Calculate of parameters involved in the measurement of mass

\subsection{Metrological comparison: Dixon, Chauvenet and Grubbs}

After remove the outliers of the original data (Tab. 1) for the Dixon, Chauvenet and Grubbs methods, it was possible to applying a statistics treatment for estimated the expanded uncertainty for four different situations: (i) original data; (ii) data after applying Dixon method; (iii) data after applying Chauvenet method and (iv) data after applying Grubbs method. This work considered four source of uncertainty to calculate the expanded uncertainty associated to measurement of mass: standard mass, resolution of instruments, uncertainty of polynomial fit and repeatability. The reference [5] shows more details about the uncertainty analyses. 
In order to show the principal results of the uncertainty analyses, the Tab. 3 summarize performing a comparison among Dixon, Chauvenet and Grubbs test. Therefore, the Fig.
2 illustrate an important reduction for each method when compared to the original data.

Table 3. Measurement uncertainty

\begin{tabular}{|c|c|c|c|c|c|c|c|}
\hline \multirow{2}{*}{$\begin{array}{l}\text { Indicated } \\
\text { mass }\end{array}$} & \multicolumn{4}{|c|}{ Expanded Uncertainty $\left(\mathrm{U}_{\mathrm{E}}\right)$} & \multicolumn{3}{|c|}{$\begin{array}{l}\text { Measurement Uncertainty Reduction } \\
\text { (MUR) }\end{array}$} \\
\hline & Original data & Dixon & Chauvenet & Grubbs & Dixon & Chauvenet & Grubbs \\
\hline kg & kg & kg & kg & kg & $\%$ & $\%$ & $\%$ \\
\hline 0.001 & 0.0024 & 0.0024 & 0.0021 & 0.0024 & $0.0 \%$ & $11.7 \%$ & $0.0 \%$ \\
\hline 1.004 & 0.0027 & 0.0027 & 0.0027 & 0.0027 & $0.0 \%$ & $0.0 \%$ & $0.0 \%$ \\
\hline 2.004 & 0.0023 & 0.0023 & 0.0019 & 0.0023 & $0.0 \%$ & $19.4 \%$ & $0.0 \%$ \\
\hline 2.996 & 0.0023 & 0.0019 & 0.0019 & 0.0019 & $17.6 \%$ & $17.6 \%$ & $17.6 \%$ \\
\hline 4.002 & 0.0027 & 0.0027 & 0.0027 & 0.0027 & $0.0 \%$ & $0.0 \%$ & $0.0 \%$ \\
\hline 5.000 & 0.0022 & 0.0022 & 0.0022 & 0.0022 & $0.0 \%$ & $0.0 \%$ & $0.0 \%$ \\
\hline 5.996 & 0.0029 & 0.0029 & 0.0019 & 0.0023 & $0.0 \%$ & $35.2 \%$ & $19.9 \%$ \\
\hline 7.007 & 0.0022 & 0.0022 & 0.0022 & 0.0022 & $0.0 \%$ & $0.0 \%$ & $0.0 \%$ \\
\hline 7.993 & 0.0037 & 0.0037 & 0.0037 & 0.0037 & $0.0 \%$ & $0.0 \%$ & $0.0 \%$ \\
\hline 9.001 & 0.0020 & 0.0019 & 0.0019 & 0.0019 & $5.4 \%$ & $5.4 \%$ & $5.4 \%$ \\
\hline 10.008 & 0.0021 & 0.0021 & 0.0021 & 0.0021 & $0.0 \%$ & $0.0 \%$ & $0.0 \%$ \\
\hline 20.002 & 0.0023 & 0.0019 & 0.0019 & 0.0019 & $17.6 \%$ & $17.6 \%$ & $17.6 \%$ \\
\hline 22.001 & 0.0020 & 0.0019 & 0.0019 & 0.0019 & $5.4 \%$ & $5.4 \%$ & $5.4 \%$ \\
\hline 24.996 & 0.0026 & 0.0026 & 0.0023 & 0.0026 & $0.0 \%$ & $9.0 \%$ & $0.0 \%$ \\
\hline 29.997 & 0.0020 & 0.0019 & 0.0019 & 0.0019 & $5.4 \%$ & $5.4 \%$ & $5.4 \%$ \\
\hline
\end{tabular}

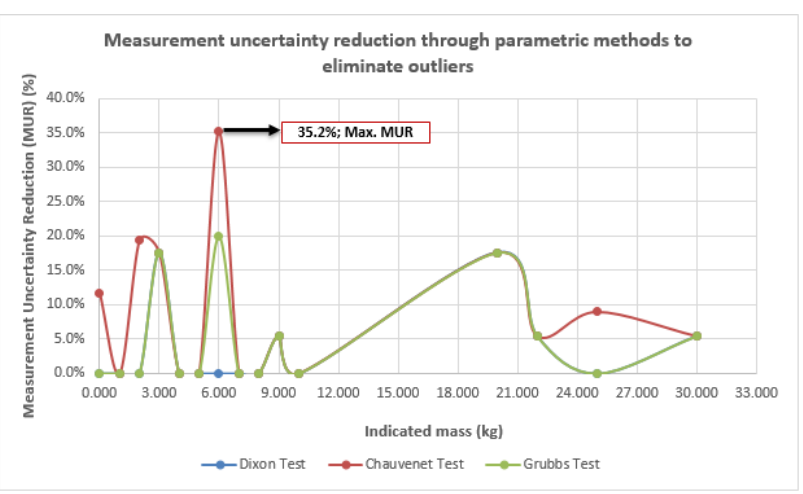

Fig. 2. Measurement uncertainty

Tab. 3 and Fig. 2 confirm that the maximum measurement reduction was offered by Chauvenet test $(35.2 \%)$. In addition, Dixon test offered a maximum uncertainty reduction in $17.6 \%$ and Grubbs for $19.9 \%$. In fact, all the parametric method for exclusion outliers applied in this work offered an important expanded uncertainty reduction when compared with the original data uncertainty show in Tab. 3.

\section{Conclusions}

This paper compared three different parametric method to eliminate outliers. These values increase the measurement uncertainty and produce systematic errors. The consolidated results confirmed that the assessed methods (Dixon, Chauvenet and Grubbs) constitute a significant strategy to reduce the expanded measurement uncertainty up to $35.2 \%$, into a confidence level of $95.0 \%$. Finally, this paper propose to include a revision and statistical analyses of outliers in the EURAMET/cg-18/v.02 and, consequently, in the Guia SIM (2009).

This is an Open Access article distributed under the terms of the Creative Commons Attribution License

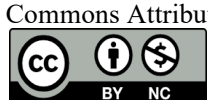

1. International Organization of Legal Metrology (OIML). OIML R76-1. Non-automatic weighing instruments. 2006.

2. EURAMET cg-18. Guidelines on the Calibration of Non-Automatic Weighing Instruments. Vol. 4.0. 2015.

3. Wang, C., Caja, J., \& Gómez, E. (2018). Comparison of methods for outlier identification in surface characterization. Measurement, 117, 312-325.

4. Oliveira, E.; De Faro, O.; Dos Santos, A.; Oliveira, C. Comparison of different approaches for detection and treatment of outliers in meter proving factors determination. Flow Measurement and Instrumentation. 2016.

\section{References}

5. Virmani, D., Jain, N., Parikh, K., \& Upadhyaya, S. (2018). Boundary Outlier Centroid Based Reduced Overlapping Image Segmentation. Journal of Engineering Science \& Technology Review, 11(5).

6. Barrios, R.; Castañeda, M. Metrological assessment of different parametric method to analyses outliers in the calibration process of non-automatic weighing instruments (in Spanish). Department of Mechanical Engineering. Universidad del Atlántico. 2018.

7. Barrios R.; Castañeda M.; Pedraza C.; Hernandez J.; Ibañez I. Outliers exclusion: a strategy to reduce the uncertainty type $A$ in the scales calibration process. CENAM. 2016.

8. GUM: Evaluation of measurement data - Guide to the expression of uncertainty in measurement. JCGM:100. 2008. 